\title{
EFECTOS DE LA DISPONIBILIDAD DE CARBONO ORGÁNICO FOTODEGRADADO Y DE NUTRIENTES MINERALES SOBRE LA ABUNDANCIA DE BACTERIAS ACTIVAS
}

\author{
Isabel Reche \\ Departamento de Biología Animal y Ecología Facultad de Ciencias, Universidad de Granada 18071 Granada, ESPAÑA
}

Palabras clave: COD fotodegradado, nutrientes minerales, bacterias activas

Key words: Photobleached DOC, mineral nutrients, active bacteria

\begin{abstract}
EFFECTS OF PHOTOBLEACHED ORGANIC CARBON AND MINERAL NUTRIENTS AVAILABILITY ON ACTIVE BACTERIA ABUNDANCE

Bacteria in aquatic ecosystems are key organisms in the processing of dissolved organic carbon (DOC). Their activity depends on organic and mineral substrate availability. Colored DOC photobleaching can be a source of bioavailable DOC. In this study, we analyzed how colored DOC photobleaching and mineral nutrient supply affect bacterial activity (cells CTC-positive). We performed a factorial experiment manipulating colored DOC photobleaching and mineral nutrients. Colored DOC photobleaching involved an increase in bacterial activity as well as mineral nutrient enrichments. In addition, there was a positive interaction between both factors. Bacteria can use more colored DOC photobleached, that is expected, under mineral nutrient enrichments. Therefore, in natural systems, eutrophication could induce a higher processing of colored DOC, at least via respiration.
\end{abstract}

\section{INTRODUCCIÓN}

Las bacterias, en sistemas acuáticos, son organismos con una doble función en el ciclo del carbono. Por un lado, oxidan directamente el carbono orgánico disuelto (COD) hasta $\mathrm{CO} 2 \mathrm{y}$ también son eslabones de transferencia de carbono dentro de la red trófica (Azam et al. 1983). El crecimiento y la actividad de estos organismos están regulados por diversos factores tanto ambientales como de limitación por recursos o depredación (Pace \& Cole, 1994). Los recursos limitantes más inmediatos de las bacterias son los compuestos de carbono orgánico y los nutrientes minerales como el fósforo (P) y el nitrógeno $(\mathrm{N})$.

El COD derivado de la excreción fitoplanctónica se ha considerando, hasta muy recientemente, como la principal fuente de energía para las bacterias. Esta visión, sin embargo, $\boldsymbol{s} \boldsymbol{e}$ está modificando al ponerse de manifiesto que las bacterias también parecen utilizar, bajo ciertas condiciones ambientales, los compuestos (generalmente no biodegradables) de origen alóctono. Estos compuestos orgánicos de origen alóctono contienen una elevada proporción de substancias húmicas que proporcionan el color amarillento-marrón existente en numerosos cuerpos de agua. La absorción de radiación solar por COD coloreado induce una serie de transformaciones que le hacen incrementar su biodegradabilidad (Strome \& Miller, 1978). La radiación solar promueve una degradación de los compuestos húmicos de elevado peso molecular a compuestos de bajo peso molecular (mayoritariamente desconocidos) que si son substratos utilizables por las bacterias. Este proceso lleva asociado una pérdida de color del COD coloreado. A pesar de que se han publicado algunos trabajos sobre la fotodegradación del C orgánico coloreado como una fuente alternativa de carbono utilizable por las bacterias (Lindell et 
al., 1995; Wetzel et al., 1995; Moran \& Zepp, 1997; Reche et $a l, 1998$ ), esta área de estudio persiste escasamente estudiada en comparación con la excreción fitoplanctónica de COD. La respuesta bacteriana a la disponibilidad de COD coloreado fotodegradado, en los trabajos mencionados, se ha cuantificado a partir de cambios en la abundancia o en la producción de bacterias y no midiendo directamente su actividad.

Las bacterias, en ambientes naturales, también pueden encontrarse limitadas por $\mathrm{P}$ o $\mathrm{N}$ en lugar de por $\mathrm{C}$ orgánico (Currie, 1990; Pace, 1993). Esta limitación por nutrientes minerales se ha relacionado con el elevado contenido de las bacterias en $\mathrm{P}$ y en $\mathrm{N}$, en comparación a su contenido en $\mathrm{C}$. Esta composición elemental implica que las bacterias tengan altos requerimientos de nutrientes minerales (Vadstein \&

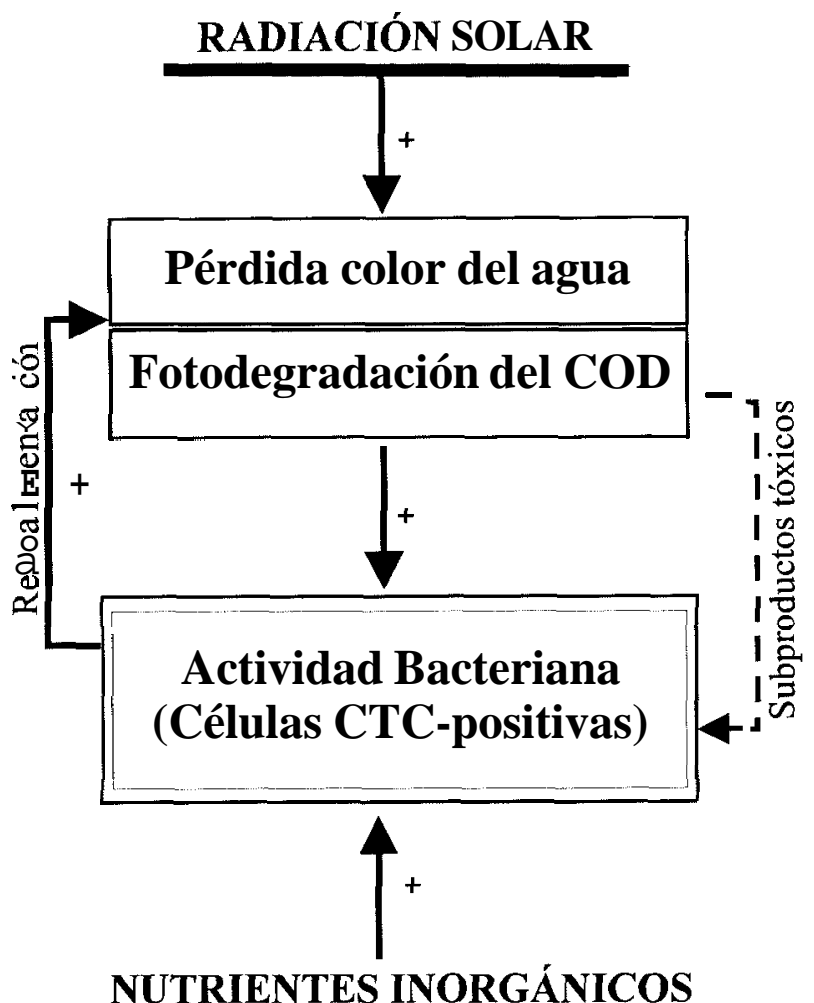

FIGURA 1. Esquema de las posibles interacciones entre la radiación solar, el COD coloreado, la abundancia de bacterias activas y los nutrientes inorgánicos. FIGURE 1. Squeme of the potential interactions amany solar radiation, colored DOC, active bacteria abundance and mineral nutrients.
Olsen, 1989; Reche et al., 1997). Desde un punto de vista funcional, la limitación del bacterioplancton por $\mathrm{P}$ o por $\mathrm{N}$ puede llegar a ser un importante controlador de la cantidad de C orgánico que éste procesa (Zweifel et al., 1995; Rivkin \& Anderson, 1997).

Todo lo expuesto hasta el momento nos lleva a hipotetizar que: la disponibilidad de COD coloreado fotodegradado supone un incremento en los recursos de C orgánico biodegradable que deberían inducir un estímulo de la actividad bacteriana; que un aumento en la disponibilidad de nutrientes minerales, bajo condiciones de no limitación por $\mathrm{C}$, debería estimular la actividad bacteriana; y que ambos procesos pueden interactuar y catalizar un mayor procesamiento de $\mathrm{C}$ orgánico (ver Figura 1). Para comprobar dichas hipótesis, en este estudio, hemos realizado un experimento factorial controlando tanto la disponibilidad de nutrientes inorgánicos (P y N) como la presencia de sustratos orgánicos procedentes de la fotodegradación de COD coloreado.

\section{ÁREA DE ESTUDIO}

El agua para realizar los experimentos se tomó de un lago húmico (Old Man McMullen Pond) localizado en Great Mountain Forest, Connecticut, Estados Unidos (41 $57^{\circ} \mathrm{N} 73^{\circ}$ $\left.15^{\prime} \mathrm{W}\right)$. Este lago presenta gran variabilidad estaciona1 en la concentración de COD y en su color (Reche et al. enviado). El período seleccionado (otoño de 1995) para realizar el experimento coincidió con máximos de la razón color: COD. Esta selección se realizó para obtener agua con una elevada proporción de ácidos húmicos como componentes del COD. Durante esta estación, la concentración de clorofila-a suele ser inferior a $2 \mu \mathrm{g}^{-1}$, por lo tanto la contribución de la excreción fitoplanctónica al total del COD se supone baja. La concentración de fósforo total estuvo próxima a $8 \mu \mathrm{g} \mathrm{P} \mathrm{l}^{-1}$ y los valores de $\mathrm{pH}$ a 4.3 .

\section{MÉTODOS}

El agua del lago se filtró a través de un Whatman GF/F ( $\mathrm{t}$ $0.7 \mu \mathrm{m}$ de tamaño de poro) para preparar los diferentes tratamientos. Este procedimiento nos permitió retirar todos los organismos bacterívoros y autotróficos. El proceso de filtración también redujo la abundancia bacteriana en aproximadamente un $50 \%$, lo que permitió realizar los cultivos de recrecimiento (Tranvik, 1988). La exclusión del fitoplancton de los cultivos supuso que el crecimiento bacteriano se basó en el C orgánico existente, en su mayor parte de naturaleza húmica. Este agua filtrada se utilizó para 
preparar 3 cultivos por cada uno de los siguientes tratamientos:

- Transparente (T), los cultivos se realizan en botellas transparentes a la mayor parte del espectro solar. Por lo tanto, las bacterias disponen de substratos orgánicos fotodegradados.

- Opaco (O), los cultivos sc realizan en botellas opacas a la radiación solar. Por lo tanto, las bacterias carecen de substratos orgánicos fotodegradados.

- Transparente más supleinento de nutrientes inorgánicos $(\mathrm{T}+)$, los cultivos se realizan en botellas transparentes y se enriquecen con $\mathrm{KH}_{2} \mathrm{PO}_{4}$ y $\mathrm{NH}_{4} \mathrm{Cl}$ a una conceiitración final de 1 y $10 \mu \mathrm{M}$, respectivamente. Por lo tanto, las bacterias disponen de substratos orgánicos fotodegradados y de nutrientes minerales en exceso.

- Opaco más suplemento de nutrientes inorgánicos $(\mathrm{O}+)$, los cultivos se realizan en botellas opacas a la radiación solar y se enriquecen con $\mathrm{KH}_{2} \mathrm{PO}_{4}$ y $\mathrm{NH}_{4} \mathrm{Cl}$ también a una concentración final de 1 y $10 \mu \mathrm{M}$. Por lo tanto, las bacterias carecen de substratos orgánicos fotodegradados pero disponen de nutrientes minerales en exceso.

Todas las botellas experimentales fueron incubadas sobre una plataforma bajo condiciones naturales de irradiación solar. A partir de cada cultivo se tomaron numerosas muestras durante el período de incubación para los análisis de COD, color del agua y abundancia de bacterias metabólicamente activas. Las dosis de radiación solar se midieron con un radiómetro modelo LiCor (LI-190 SB).

La concentración de COD se analizó filtrando la muestra por un Whatman GF/F precombustionado y acidificando hasta un $\mathrm{pH}=2$, entonces, la muestra fue medida en un analizador de carbono (Shimadzu TOC-5050).

El color del agua se midió, tras filtrar la muestra por un Whatman GF/F, como la absorbancia del filtrado a $440 \mathrm{~nm}$ en cubetas de $10 \mathrm{~cm}$. Los valores de absorbancia (A) se convirtieron en coeficientes de absorción $\left(\mathrm{a}, \mathrm{m}^{-1}\right.$ ) siguiendo a Cuthbert \& del Giorgio (1992):

$$
a=2.303 \mathrm{~A} / \mathrm{r}
$$

donde res la longitud de la cubeta (en m).

La abundancia de bacterias metabólicamente activas fue determinada usando el método propuesto por Rodríguez et al. (1992). Este método utiliza el cloruro de 5-ciano-2,3-ditolyl tetrazolium (CTC) como un indicador de la actividad del sistema de transporte electrónico en células respirando. El CTC oxidado carece de color y no es fluorescente, sin embargo, cuando se reduce (vía el sistema de transporte electrónico) se forma un formazan insoluble y fluorescente que se acumula intracelularmente. Las bacterias que lo contienen están activas y pueden visualizarse con microscopia de epifluorescencia. El procedimiento utilizado consistió en: inmediatamente después de tomar las muestras $(5 \mathrm{ml})$ en tubos estériles, se les añadió CTC (50 mM) hasta una concentración final de $5 \mathrm{mM}$; se dejaron incubar y reaccionar en oscuridad a $20^{\circ} \mathrm{C}$ durante $8 \mathrm{~h}$ y se fijaron con formaldehído (a una concentración final del $5 \%$ ). Posteriormente, de las muestras se tomaron alícuotas de $2 \mathrm{ml}$ y se filtraron a través de un filtro negro Nuclepore dc $0.22 \mu \mathrm{m}$ de diámetro y con los filtros se moniaron las preparaciones. Las bacterias activas, que fluorecen rojas, se enumeraron en un microscopio de epifluorescencia provisto con el conjunto de lentes para la rodainina. Paralelamente se analizaron controles (fijados con formaldehído antes de la adición del CTC) para cuantificar posibles contaminaciones o la existencia de picoplancton autótrofo que también fluorece en rojo.

\section{RESULTADOS}

Los valores de carbono orgánico disuelto fueron bastante constantes, oscilando alrededor de $17 \mathrm{mg} \mathrm{l}^{-1}$, independientemente del tratamiento considerado y de la dosis de radiación recibida (Figura 2, círculos negros). Por el contrario, los valores del coeficiente de color (cuadrados blancos) fueron significativarnente diferentes entre los tratamientos que permitieron el paso de la radiación solar $(\mathrm{T}$ y $\mathrm{T}+$ ) y aquellos que fueron opacos a la misma (O y $\mathrm{O}+$ ) (Figura 2). En los tratamientos $\mathrm{T}$ y $\mathrm{T}+$ hubo una pérdida exponencial del color del agua a medida que la dosis de radiación solar recibida fue mayor, pasando de valores iniciales próximos a $12 \mathrm{~m}^{-1}$ hasta valores finales de casi $8 \mathrm{~m}^{-1}$. Esta pérdida de color fue similar en ambos tratamieiitos. Sin embargo, el color del agua en los tratamientos $\mathrm{O}$ y $\mathrm{O}+$ sólo se redujo levemente sin alcanzar nunca valores inferiores a $10.5 \mathrm{~m}^{-}$.

Estos resultados demuestran que las cualidades ópticas del COD se modificaron bajo exposición a la radiación solar en los tratamientos $\mathrm{T}$ y $\mathrm{T}+\mathrm{y}$ no lo hicieron en los tratamientos $\mathrm{O}$ y $\mathrm{O}+$. Esta reducción en la capacidad para absorber la radiación solar está relacionada con la degradación de lugares cromofóricos aumentando en la biodegradabilidad del COD. La pérdida del color del agua incrementó de forma exponencial a medida que la dosis de radiación fue mayor. La similaridad en los patrones de pérdida de color entre $\mathrm{T}$ y $\mathrm{T}+\mathrm{y}$ entre $\mathrm{O}$ y $\mathrm{O}+$ sugiere que la adición de nutrierites iiiorgánicos no parece afectar a las cualidades ópticas del COD y que este proceso fue básicamente abiótico.

Por otro lado, la pérdida del color del agua en los tratamientos transparerites no llevó asociada una pérdida de COD. 

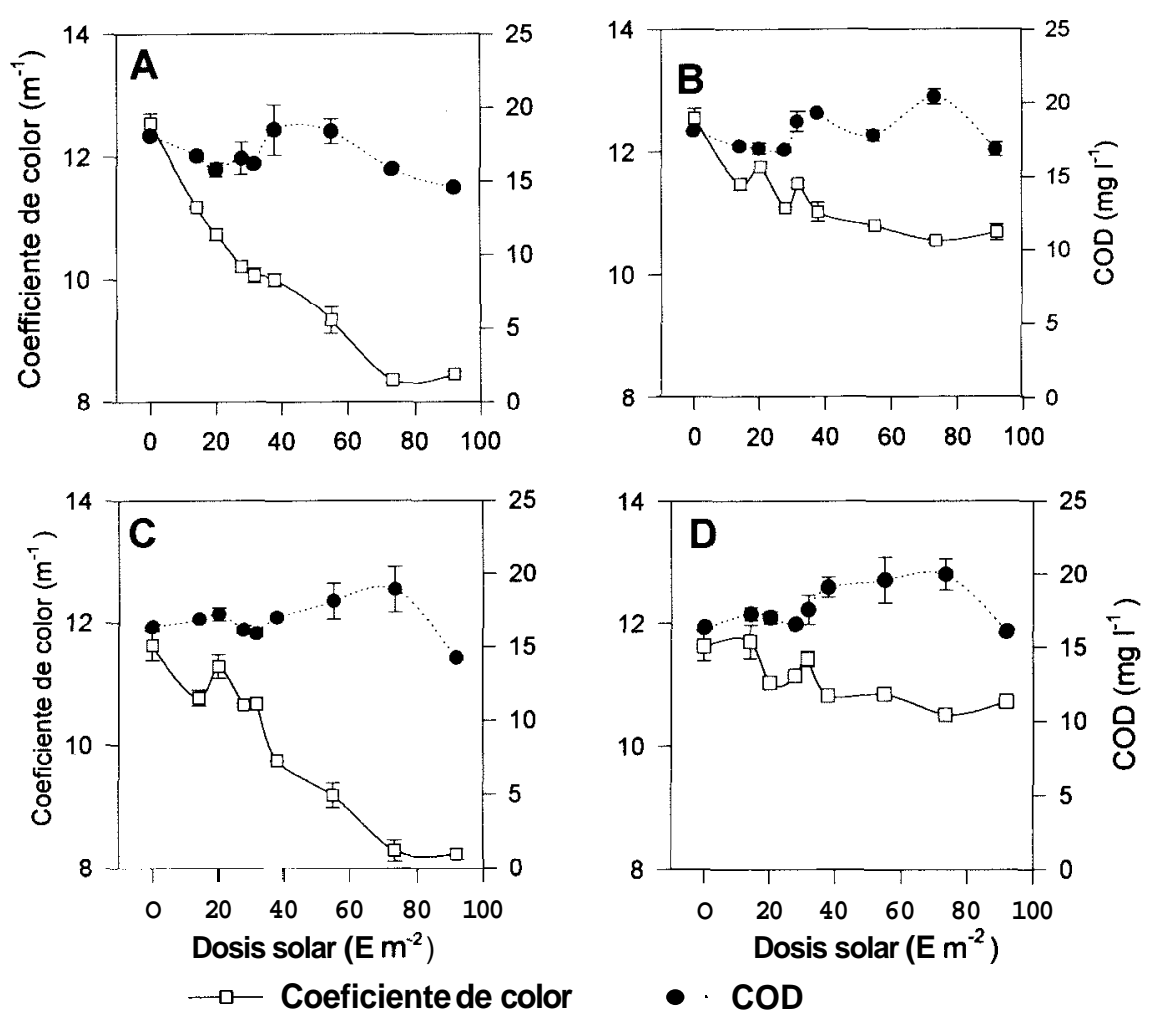

FIGURA 2. Cambios en los valores del coeficiente de color y de la concentración de COD a diferentes dosis de radiación solar durante la incubación de los cuatro tratamientos transparente (A), opaco (B), transparente más nutnentes minerales $(\mathrm{C})$ y opaco más nutrientes minerales (D).

FIGURE 2. Changes in absorptivity and DOC concentration under different sunlight doses during the incubations of the far breatments: transparent (A) opaque (B), transparent plus mineral nutrients (C) and opaque plus mineral nutnents (D).

Por lo tanto, el carbono fotodegradado perdió su color, pero la oxidación no fue completa y no supuso una pérdida de COD como $\mathrm{CO}_{2}$.

Para determinar si la presencia de substratos orgánicos procedentes de la fotodegradación del COD coloreado y la adición de nutrientes minerales afectaron a la actividad bacteriana, se cuantificó la abundancia de bacterias que están activamente respirando (células CTC-positivas) en los diferentes tratamientos y en tres momentos del período de incubación. Los resultados obtenidos se muestran en la Figura 3. Se observó que las bacterias fueron más activas en los tratamientos que recibían radiación solar y por lo tanto había disponibilidad de sustratos orgánicos fotodegradados, llegando a incrementarse la abundancia de bacterias activas hasta cuatro veces $(\mathrm{T})$ y casi seis veces $(\mathrm{T}+)$ al final de la incubación. También se apreció que en los tratamientos que fueron complementados con nutrientes minerales $(\mathrm{T}+\mathrm{y} \mathrm{O}+$ ) la abundancia de bacterias activas siempre fue mayor que la abundancia en sus cultivos equivalentes sin nutrientes minerales ( $\mathrm{T}$ y $\mathrm{O}$ ).
Para comprobar si estas diferencias en la abundancia de bacterias activas entre tratamientos fue estadísticamente significativa al final del período de incubación se realizó un análisis normalizado de la varianza (ANOVA). La comparación entre la abundancia de bacterias activas en los tratamientos transparentes $(\mathrm{T}$ y $\mathrm{T}+$ ) frente a los opacos $(\mathrm{O}$ y $\mathrm{O}+$ ) nos indica si la fotodegradación del COD coloreado la afecta significativamente. La comparación entre la abundancia de bacterias activas en los tratamientos enriquecidos $(\mathrm{T}+\mathrm{y} \mathrm{O}+$ ) frente a los no enriquecidos ( $\mathrm{T}$ y 0 ) nos indica si la adición de nutrientes minerales afecta significativamente a la actividad bacteriana. Las combinaciones de ambos factores también se analizaron para comprobar si la abundancia de bacteria activas se incrementa (interacción positiva) más allá de lo esperable por la acción conjunta de ambos factores. Los resultados obtenidos se muestran en la Tabla 1. Tanto la presencia de substratos orgánicos fotodegradados como la disponibilidad de nutrientes minerales supuso un incremento significativo en la abundancia de bacterias CTC-positivas. Además entre ambos factores existió una interacción significativa y positiva que sugiere un efecto sinergético entre ambos factores. 


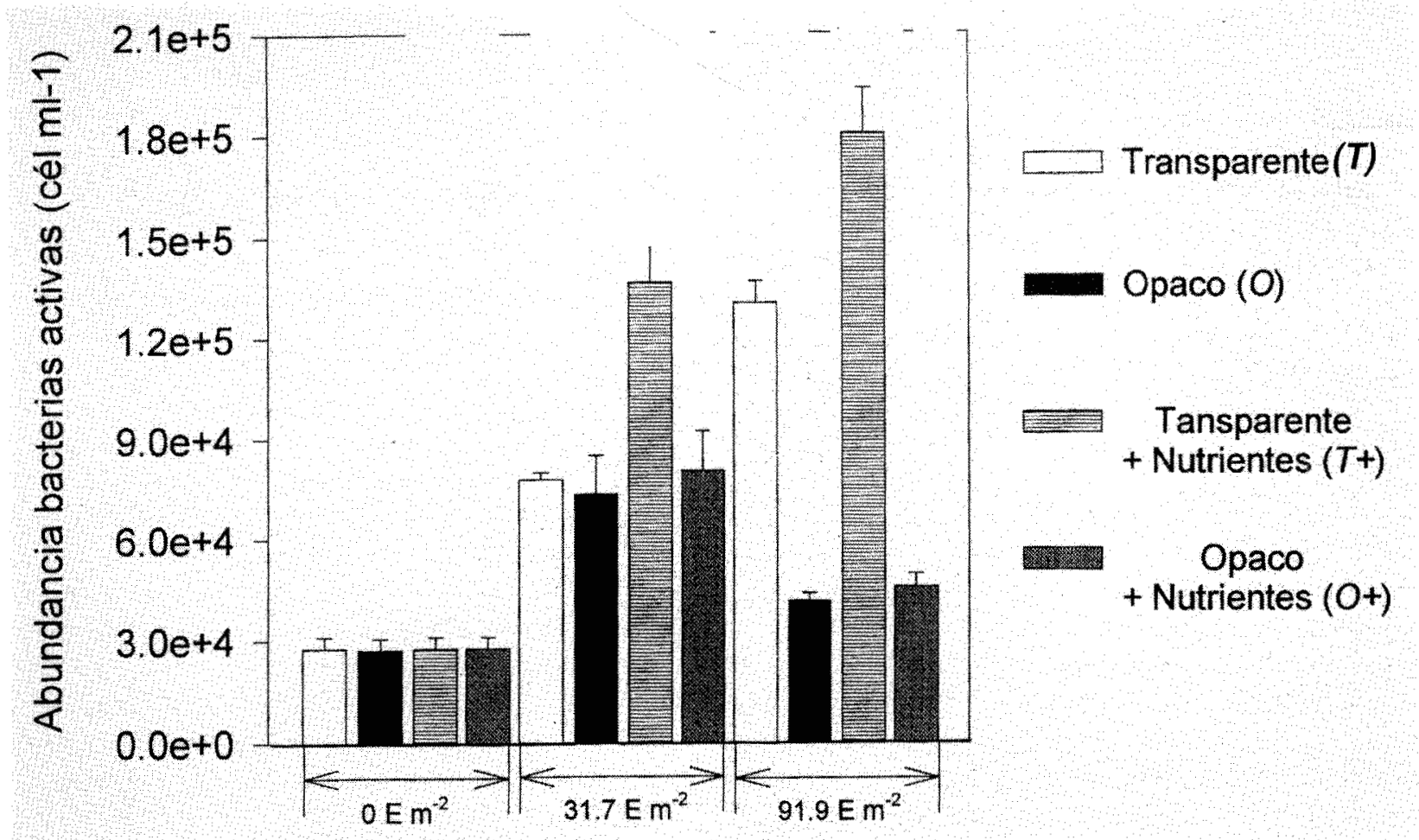

FIGURA 3. Valores de la abundancia de bacterias activas en los diferentes tratamientos al inicio (O E m²), hacia la mitad (31.7 m-') y al final (91.9 E m-') del período de incubación.

FIGURE 3. Valves of the active bacteria abundance fot the different treatments, at the begining $\left(\mathrm{O} \mathrm{E} \mathrm{m}^{2}\right)$, in the middle $\left(31.7 \mathrm{~m}^{\mathrm{i}}\right)$ and at the end $(91.9 \mathrm{E}$ m') of incubation period.

TABLA 1. Resultados del ANOVA realizado para determinar el efecto de la presencia de COD coloreado fotodegradado y de la adición de nutrientes minerales sobre la abundancia de bacterias activas (CTC-positiva). +=>efecto estimulador; $\mathrm{F} \Rightarrow$ razón de varianza; ${ }^{*} \mathrm{p}<0.05 ; * * \mathrm{p}<0.01 ;{ }^{* * *} \mathrm{p}<0.001$.

TABLE 1. Resuts of ANOVA carried out to determine the effect of photobleached colored-DOC availabiltity and mineral nutrients additions on activel (CTC-positive) bacteria abundance $+=>$ positive effect, $F=>$ variance ratio.

\begin{tabular}{l|ccc} 
& Efecto & F & p-leve1 \\
\hline \hline Substratos orgánicos fotodegradados Presencia vs Ausencia & + & 205.7 & $<0.001$ \\
Nutrientes Inorgánicos Presencia vs Ausencia & & 11.8 & $0.009 * *$ \\
Interacción & + & 8.8 & 0.018 *
\end{tabular}




\section{DISCUSIÓN}

El COD coloreado fotodegradadado, como refleja la pérdida de su color, afectó positivamente a la actividad bacteriana. Estas pérdidas son similares a las observadas en otros estudios (Strome and Miller, 1978, Lindell et al., 1995, Reche et al. 1999). Este incremento en el número de bacterias activas puede estar relacionado con las traiisformaciones sufridas por el substrato durante su exposición a la luz solar. La absorción de la radiación solar por el COD coloreado implica cambios tanto en su tainaño (pasando de cornpuestos de alto peso molecular a cornpuestos de bajo peso molecular) como en su composición (Kieber et al., 1990; Wetzel et al., 1995; Corin et al., 1996) que parecen facilitar su incorporación por las bacterias.

Por otro lado, la fotodegradación podría, adeinás, acelerar la utilización por las bacterias de COD coloreado vía cometabolismo. Este proceso se define como la degradación inicrobiana de sustancias no biodegradables debido a la presencia de sustratos de fácil asimilación (de Haan, 1977). De entre los pocos fotoproductos identificados (Corin et al., 1996; Moran \& Zepp, 1997), algunos de ellos son de uso inmediato para las bacterias. La mayoría de los compuestos identificados contienen tres o muy pocos átomos de $\mathrm{C}$ y suelen tener un peso molecular inferior a 100. Estos cornpuestos orgánicos de bajo peso molecular podrían actuar como cometabolitos y eatalizando el uso de otros compuestos más recalcitrantes.

En ensayos experimentales (Lindell et al., 1995; Moran \& Zepp, 1997; Reche et al., 1998) o en condiciones in situ (Lindell et al. 1996) también se ha observado un efecto estimulador de la presencia de fotoproductos sobre la abundancia total de bacterias. Sin embargo, este efecto estimulados no es tan evidente en el caso de la produccióri bacteriana (Lindell et al., 1996; Reche et al., 1998). Este efecto más variable sobre la producción bacteriaiia parece estar relacionado con la importancia relativa de otros procesos derivados de la exposición a la radiación solar como, por ejemplo, la acumulación de subproductos tóxicos (Scully et al., 1996) o el daño en el DNA celular (Aas et al., 1996) o dependientes de la variabilidad en la razón color: COD (Reche et al., 1999).

La adición de nutrientes minerales también supuso un incremento significativo en la abundancia de bacterias activas. Este resultado apunta la existencia de una limitación de las bacterias por $\mathrm{P}$ y/o N. La limitación del bacterioplancton por recursos minerales ha sido observada en numerosas ocasiones en ambientes naturales (Currie, 1990; Morris \& Lewis, 1992; Pace, 1993) y se ha sugerido como un mecanismo de control en el procesainiento total de carbono orgánico (Zweifel et al., 1995; Rivkin \& Anderson, 1997). Está bien establecido que las bacterias, debido a su composición elemental, tienen elevados requerimientos de P y N (Vadstein \& Olsen, 1989; Reche et al., 1997). Por lo tanto, la reducción en la limitación por nutrientes minerales promovió un incremento en la actividad bacteriana que se podría traducir en un mayor procesamiento de COD vía respiración. Este hecho sugiere que procesos como la eutrofización de sisteinas acuáticos podrían modificar el ciclado de carbono orgánico vía activación de bacterias.

El resultado, sin duda, más significativo fue la existencia de una interacción positiva entre la presencia de sustratos fotodegradados y la de nutrientes inorgánicos (Tabla 1). Esta interacción indica que la actividad bacteriana incrementó inás de lo esperable por la acción conjunta de ambos factores. Este efecto sinergético había sido previamente sugerido para la abundancia total de bacterias (Reche et al., 1998) pero no había sido cuantificado en términos de abundancia de bacterias activas (CTC-positivas). Son nuinerosas las explicaciones que podrían justificar este efecto sinergético: limitación conjunta o concurrente de diversos eleinentos como $\mathrm{C}, \mathrm{P}$ o N; cometabolisino entre diferentes compuestos suininistradores de recursos minerales y orgánicos; retroalimentacioiies biológicas relacionadas con la activación de cadenas enzimáticas, etc (De Haan, 1977; De Angelis et al., 1986; Morris \& Lewis, 1992). Sin embargo, ninguna de ellas ha sido coinprobada directamente.

La extrapolación de estos resultados experimentales a las condiciones naturales debe realizarse con precaución. En el experimento realizado, al ser excluido el fitoplancton, se simplificó el número de interacciones posibles, pues en ambientes naturales son numerosas las interacciones entre éste, las bacterias, el COD y los nutrientes minerales. El diseño de experimentos que incluyan este eslabón, así como la comparación entre lagos con diferente estado trófico, abundancia bacteriana, concentración de nutrientes minerales y de las tasas de 'fotodegradación de COD coloreado podrán permitirnos una mejor valoración de la importancia relativa de los sustratos orgánicos fotodegradados frente a los de origen autotrófico bajo diferentes condiciones de eutrofización.

\section{AGRADECIMIENTOS}

Este trabajo fue realizado en colaboración con los Drs. M.L. Pace y J.J. Cole durante mi estancia en el Institute of Ecosystem Studies (USA), financiada por una beca postdoctoral del MEC. Agradezco la ayuda que D. Thomas y D. Fisher me proporcionarori en el laboratorio. 


\section{BIBLIOGRAFÍA}

Aas P., Lyons M. M., Pledger R., Mitchell D. L., Jeffrey W. H. (1996). Inhibition of bacterial activities by solar radiation in nearshore waters and the Gulf of Mexico. Aquat. Microb. Ecol. 11: 229-238

Azani F., Fenchel T., Field J.G., Gray J.S., Meyer-Reil L.-A., Thingstad F. (1983). The ecological role of water-column rnicrobes in the sea. Mar. Ecol. Prog. Ser. 10: 257-263

Corin N., Backlund P., Kulovaara M. (1996) Degradatiori products formed during UV-irradiation of waters. Chemosphere 33: 245-255

Currie D.J. (1990) Large-scale variability and interactions among phytoplankton, bacterioplankton, and phosphorus. Limnol. Oceanogr. 35: 1437-1455

Cuthbert I.D., del Giorgo P. (1992) Toward a standard method of measuring color in freshwater. Limnol. Oceanogr. 37: 1319-1326

De Angelis D.L., Post W.M., Travis C.C. (1986) Positive feedback in natural systems. Springer-Verlag Berlin Heidelberg $290 \mathrm{pp}$

Haan H. de (1977) Effect of benzoate on rnicrobial decomposition of fulvic acids in Tjeukemeer (the Netherlands). Limnol. Oceanogr. 22: 38-44

Kieber D.J., Zhou X., Mopper K. (1990) Formation of carbonyl compounds from UV-induced photodegradation of humic substances in natural waters: Fate of riverine carbon in the sea. Limnol. Oceanogr. 35: 1503-1515

Lindell M.J., Granéli W., Tranvik L.J. (1995) Enhanced bacterial growth in response to photochemical transformation of dissolved organic matter. Lirnnol. Oceanogr. 40: 195-199.

Lindell M.J., Granéli W., Tranvik L.J. (1996) Effect of sunlight on bacterial growth in lakes of different huinic content. Aquat. Microb. Ecol. 11: 135-141

Moran M.A. , Zepp R.G. (1997) Role of photoreactions in the formation of biologically labile compounds from dissolved organic matter. Limnol. Oceanogr. 42: 1307-1316.

Morris D.P., Lewis W.M. Jr (1992) Nutrient limitation of bacterioplankton growth in Lake Dillon, Colorado. Limnol. Oceanogr. 37: 1179-1192.

Pace M.L. (1993) Heterotrophic microbial processes. In: Carpenter SR, Kitchell JF (eds) The trophic cascade in lakes. Cambrigde University Press, New York, pp 252-277
Pace M.L., Cole J.J. (1994) Comparative and experimental approaches to top-down and bottom-up regulation of bacteria. Microb. Ecol. 28: 181-193.

Reche I., Carrillo P., Cruz-Pizarro L. (1997) Influence of metazooplankton on interactions of bacteria and phytoplankton in an oligotrophic lake. J. Plank. Res. 19: 631-646

Reche I., Pace M.L., Cole J.J. (1998) Interactions of photobleaching and inorganic nutrients in determiiiing bacterial growth on colored dissolved organic carbon. Microb. Ecol. 36, 270-280

Reche I., Pace M.L., Cole J.J. (1999) Relationship of trophic and chemical conditions to photobleaching of dissolved organic matter in lake ecosystems. Biogeochemistry 44, 259-280.

Rodríguez G.G., Phipps D., Ishiguro K. \& Ridgway H.F. (1992). Use of a fluorescent redox probe for direct visualization of actively respiring bacteria. App. Eriviron. Microbiol. 58: 1801-1808.

Rivkin R.B., Anderson M.R. (1997) Inorganic nutrient limitation of oceanic bacterioplankton. Limnol. Oceanogr. 42: $730-740$

Scully N.M., McQueen D.J., Lean D.R.S., Cooper W.J. (1996) Hydrogen peroxide forrnation; The interaction of ultraviolet radiation and dissolved organic carbon in lake waters along a $43-75 \% \mathrm{~N}$ gradient. Limnol. Oceanogr. 41: 540-548

Strome D.J., Miller M.C. (1978) Photolytic changes in dissolved humic substances. Verh. Internat. Verein. Limnol. 20: $1248-1254$

Tranvik L.J. (1988) Availability of dissolved organic carbon for planktonic bacteria in oligotrophic lakes of differing humic content. Microb. Ecol. 16: 311-322

Vadstein O.\& Olsen Y. (1989) Chemical cornposition and phosphate uptake kinetics of limnetic bacterial communities cultered in chemostat under phosphorus limitatiori. Limnol. Oceanogr. 34: 939-946

Wetzel R.G., Hatcher P.G., Bianchi T.S. (1995) Natural photolysis by ultraviolet irradiance of recalcitrant dissolved organic matter to simple substrates for rapid bacterial metabolism. Lirnnol. Oceanogr. 40: 1369-1380

Zweifel U.L., Wikner J., Hagström A., Lundberg E., Norrman B. (1995) Dynamics of dissolved organic carbon in a coastal ecosystem. Lirnnol. Oceanogr. 40: 299-305. 
